\section{Evolution of sex}

THIS is an important and infuriating book*. It is important because it is a scholarly and sustained attack on the most important problems in evolutionary biology; the evolution of genetic mechanisms, of sexual dimorphism and of society. It is infuriating because it fails, narrowly but decisively, to provide the illumination promised by the first two chapters.

The problem which Ghiselin sets out to cover is more easily stated than solved. In Darwin's theory of natural selection we have an explanation of evolution in terms of the success or failure of individuals to survive and leave descendants. As an explanation of characteristics which promote individual survival and reproduction, this is fully satisfactory. But sex and genetic recombination are often interpreted in terms of their contribution to the survival of the species and not of the individual, and social behaviour in terms of the survival of the community. How is the evolution of such characteristics to be explained? Two positions seem possible. The first, the "group selection" explanation, is to argue that selection between specics (that is, the survival and division of some species and the extinction of others) produces genetic mechanisms adapted to ensure species survival. The second, strongly espoused by Ghiselin, is that sexual adaptations evolve because of the advantages they give to the survival and reproduction of individuals-- that is, by natural selection in Darwin's sense.

Ghiselin has qualities which adapt him for tackling these questions. His philosophical position is sound (that is, I agree with it); he distrusts teleological explanation, despises Baconian induction, and regards holism as an illegitimate attempt to smuggle teleology back into biology. He has a sensitive nose for Panglossianism, which can be defined as the belief that the characteristics of organisms exist to ensure the survival of species and of ecological communities. Although accusations of Panglossianism are usually indignantly denied, such views are widespread among evolutionists, ecologists and ethologists, as Ghiselin makes clear. Equally important, he has the widespread knowledge of natural history which is needed to test evolutionary hypotheses.

Why then does he fail? Ultimately, because he does not think as a geneticist, and because he abjures mathematical language. He rightly remarks that if a mathematical model fails to

*The Economy of Nature and the Evolution of Sex. By Michael T. Ghiselin. Pp. xii +346 . (University of California: Berkeley, Los Angeles and London, December 1974.) $\$ 12.05$; $£ 7.10$.

Understanding Homosexuality: Its Bio- modelled experiences are likely to be logical and Psychological Bases. Edited relevant-as they are for all kinds of by J. A. Loraine. Pp. 217. (Medical and behaviour. Freund et al. report an Technical Publishing: Lancaster, October 1974.) £6.50.

Homosexual behaviour is of major interest both scientifically-because of the general problems of the sources of sexual preference, gender identity and gender behaviour--and socially, because of the legal, occupational and other disadvantages suffered by those whose preference is homosexual. Three of the chapters in this book fall under the scientific heading and five under the social heading; the remaining chapter is concerned with venereal disease and homosexuality.

Two of the scientific chapters are reviews, one mainly on males, by Cooper, and one solely on females, by Kenyon. Both are reasonably adequate on the biological sources of homosexual behaviour-Kenyon particularly soand on parent-child relationships, but neither pays more than passing attention to the potential contribution of the psychology of learning to the acquisition and maintenance of homosexual behaviour. Classical and instrumental paradigms and direct as well as population". interesting series of experiments which sought, but did not find, evidence for bisexuality of response. In all three scientific chapters almost all reported studies compared heterosexuals with undifferentiated homosexuals, rather than using the heuristically more useful division into primary (life long) and secondary (non life long) homosexuals.

The remaining chapters are concerned with the legal, theological, and general social responses of the heterosexual majority to the homosexual minority. Grey contributes a particularly thoughtful, sane and eloquent plea for the equality of status of all sexual variations involving consenting partners, both as objects of scientific study and in terms of social esteem. Ramsay and others describe the rapid progress towards equal status in Holland. A final chapter, on the status of the homosexual, by Chew et al., skims rapidly over both social and scientific aspects and includes the provocative assertion that heterosexuality is the "primary cause" of the "dilemma of over-

predict the nature of reality, it is the model which must be changed. But models do make clearer what is being assumed (even if tacit or unconscious assumptions are made, as is often the case, a careful examination of the model will usually reveal them), and they show more certainly whether the conclusions follow from the assumptions. Ghiselin seems to me to fall down on both these points. For example, on page 69 he offers an explanation for the association between diploidy and complex multicellular structure. I simply cannot form a clear picture of the genetic and selective mechanisms being proposed.

On the still more crucial point of the short-term individual advantage of sex, my difficulty is different. I do understand, in a very vague way it is true, what is being proposed. The snag is that I am familiar with several attempts to make these proposals more precise. It turns out that the conclusion-an immediate advantage for sex-seems to follow only if one makes rather extreme and implausible assumptions. Ghiselin would presumably retort: so much the worse for the model. Oddly enough, I agree with him. Plausible models giving an individual advantage to sex may well be possible; Williams and Mitton have made a promising start. But it simply does not do to ignore the difficulty and to appeal to nature as a witness. If we do not have a clearly formulated theory we do not know which facts support it.
Ghiselin's reluctance to think genetically lets him down in other contextsfor example, in his discussions of the role of kin selection in the evolution of societies, and of Fisher's idea of a positive feedback on female choice in sexual selection (it is uncharacteristic that he does not ascribe that idea to Fisher; one of his virtues is his respect for history). Thus, he seems to regard kin selection as a needless complication, only to be invoked if nothing else will do. I would argue that it is a process which is bound to operate whenever relatives live close to one another, and which therefore must be considered in any discussion of the evolution of societies. I suspect Ghiselin would dismiss this as a priorism; in fact, I am asserting that if we accept the (empirically tested) theories of genetics, then certain things follow, among them Fisher's and Hamilton's arguments. Of course, the relative importance of these and other processes have to be investigated in particular cases.

There is much in the book that is stimulating and illuminating, particularly in the discussion of sexual selection. But in some ways Ghiselin invites an ungenerous review. $\mathrm{He}$ is curiously dismissive of other people's ideas, with the exception of Darwin's. It is true that Panglossianism is rife, but it is not universal. Other evolutionists have been attempting non-teleological explanations of these phenomena. Ghiselin may have more allies than he thinks. J. Maynard Smith 